\title{
Partners review progress of Koshi Basin Programme at IGSNRR, Beijing, China on February 11-12, 2015
}

The Koshi Basin Programme (KBP) China National Review Workshop was successfully held on February 11-12, 2015 at the Institute of Geographic Sciences and Natural Resources Research (IGSNRR), Chinese Academy of Sciences (CAS) in Beijing, China. The workshop was jointly organized by IGSNRR and the International Centre for Integrated Mountain Development (ICIMOD) with support from the Australian Government through the Department of Foreign Affairs and Trade (DFAT). The Department of Land Change Science and Bio-geography, IGSNRR (CAS) hosted this two-day workshop, which aimed to share collaborative activities, discuss the KBP's progress to date, enhance the effectiveness of the programme through active participation of key stakeholders, take stock of science outcomes, and generate desirable impacts.

Prof. Zhang Yili from the Department of Land Change Science and Bio-geography, IGSNRR (CAS) chaired the opening ceremony. Together with Prof. Liu Yi, Deputy Director of IGSNRR, Prof. Wu Ning from ICIMOD and Dr. Wang Zhengyu from CAS welcomed all the participants and extended their best wishes for a successful partnership between IGSNRR, CAS and ICIMOD. Over 40 participants from 15 institutions including IGSNRR, Institute of Mountain Hazards and Environment, Cold and Arid Regions Environmental and Engineering Research Institute, Peking University, National Natural Science Foundation of China, Yunnan Institute of Environmental Sciences, World Wide Fund for Nature China, Monsoon Asia Integrated Regions Studies, China Dialogue and others attended the workshop.

During the two-day workshop, participants discussed some key issues in the Koshi River basin. They shared their knowledge and ideas on topics like ecosystem services, water induced hazards, livelihood promotion, GLOF, climate change, land use and land cover change (LULCC), and soil erosion. Participants were later divided into three thematic groups to revisit the impact pathway: disaster risk reduction (DRR), LULCC and erosion, and ecosystem services and livelihood. The discussions were very fruitful in terms of identifying who would use the scientific outcomes, how those outcomes could lead to pragmatic solutions, and how research could inform policy for collective impact. Further, the meeting outlined future work plans for the collaborative projects between ICIMOD and IGSNRR.

The workshop successfully met its expected outcomes. It helped improve knowledge of water management issues, DRR, LULCC, and livelihood promotion in the Koshi River basin. The impact pathway was updated to enhance understanding of the science-policy nexus. The workshop not only generated important scientific knowledge but also provided an opportunity for current and potential partners to share their research progress, challenges and experiences related to issues in the Koshi River basin.

(More information about the KBP is available at: www.icimod.org/kbp)

(Basanta PAUDEL and Rongkun LIU)

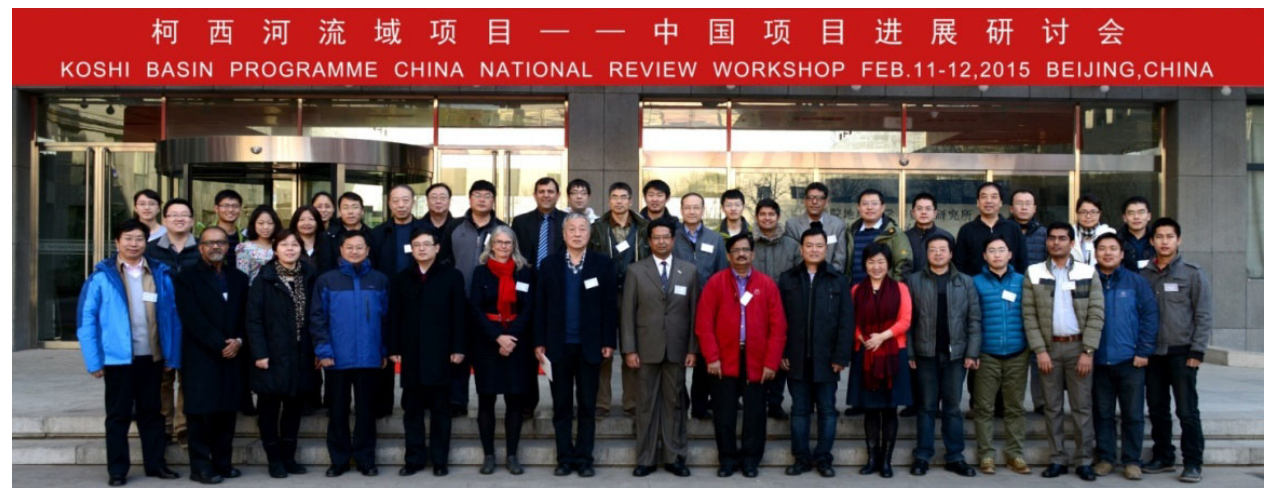

Participants of the Workshop (Photo by Jianhua SUN) 